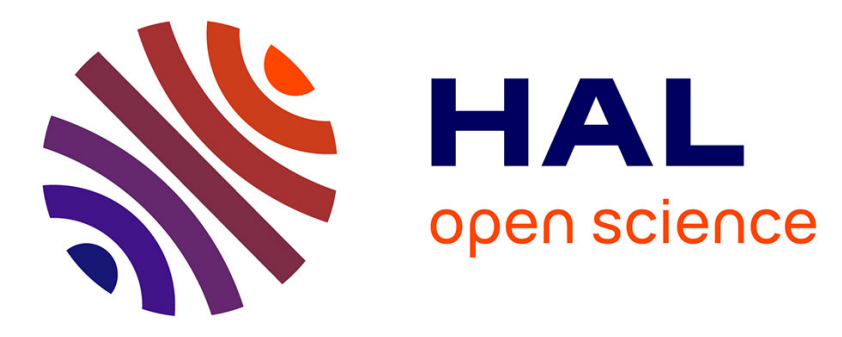

\title{
Computer and Computing Technologies in Agriculture $\mathrm{X}$
}

Daoliang Li

\section{To cite this version:}

Daoliang Li. Computer and Computing Technologies in Agriculture X: 10th IFIP WG 5.14 International Conference, CCTA 2016, Dongying, China, October 19-21, 2016, Proceedings. Springer International Publishing, AICT-509, 2019, IFIP Advances in Information and Communication Technology, 978-3-030-06154-8. 10.1007/978-3-030-06155-5 . hal-02179957

\section{HAL Id: hal-02179957 \\ https://hal.inria.fr/hal-02179957}

Submitted on 11 Jul 2019

HAL is a multi-disciplinary open access archive for the deposit and dissemination of scientific research documents, whether they are published or not. The documents may come from teaching and research institutions in France or abroad, or from public or private research centers.
L'archive ouverte pluridisciplinaire HAL, est destinée au dépôt et à la diffusion de documents scientifiques de niveau recherche, publiés ou non, émanant des établissements d'enseignement et de recherche français ou étrangers, des laboratoires publics ou privés.

\section{(ㄷ)(1)}

Distributed under a Creative Commons Attribution| 4.0 International License 


\section{IFIP Advances in Information and Communication Technology}

\section{Editor-in-Chief}

Kai Rannenberg, Goethe University Frankfurt, Germany

\section{Editorial Board}

TC 1 - Foundations of Computer Science

Jacques Sakarovitch, Télécom ParisTech, France

TC 2 - Software: Theory and Practice

Michael Goedicke, University of Duisburg-Essen, Germany

TC 3 - Education

Arthur Tatnall, Victoria University, Melbourne, Australia

TC 5 - Information Technology Applications

Erich J. Neuhold, University of Vienna, Austria

TC 6 - Communication Systems

Aiko Pras, University of Twente, Enschede, The Netherlands

TC 7 - System Modeling and Optimization

Fredi Tröltzsch, TU Berlin, Germany

TC 8 - Information Systems

Jan Pries-Heje, Roskilde University, Denmark

TC 9 - ICT and Society

David Kreps, University of Salford, Greater Manchester, UK

TC 10 - Computer Systems Technology

Ricardo Reis, Federal University of Rio Grande do Sul, Porto Alegre, Brazil

TC 11 - Security and Privacy Protection in Information Processing Systems

Steven Furnell, Plymouth University, UK

TC 12 - Artificial Intelligence

Ulrich Furbach, University of Koblenz-Landau, Germany

TC 13 - Human-Computer Interaction

Marco Winckler, University Paul Sabatier, Toulouse, France

TC 14 - Entertainment Computing

Matthias Rauterberg, Eindhoven University of Technology, The Netherlands 


\section{IFIP - The International Federation for Information Processing}

IFIP was founded in 1960 under the auspices of UNESCO, following the first World Computer Congress held in Paris the previous year. A federation for societies working in information processing, IFIP's aim is two-fold: to support information processing in the countries of its members and to encourage technology transfer to developing nations. As its mission statement clearly states:

IFIP is the global non-profit federation of societies of ICT professionals that aims at achieving a worldwide professional and socially responsible development and application of information and communication technologies.

IFIP is a non-profit-making organization, run almost solely by 2500 volunteers. It operates through a number of technical committees and working groups, which organize events and publications. IFIP's events range from large international open conferences to working conferences and local seminars.

The flagship event is the IFIP World Computer Congress, at which both invited and contributed papers are presented. Contributed papers are rigorously refereed and the rejection rate is high.

As with the Congress, participation in the open conferences is open to all and papers may be invited or submitted. Again, submitted papers are stringently refereed.

The working conferences are structured differently. They are usually run by a working group and attendance is generally smaller and occasionally by invitation only. Their purpose is to create an atmosphere conducive to innovation and development. Refereeing is also rigorous and papers are subjected to extensive group discussion.

Publications arising from IFIP events vary. The papers presented at the IFIP World Computer Congress and at open conferences are published as conference proceedings, while the results of the working conferences are often published as collections of selected and edited papers.

IFIP distinguishes three types of institutional membership: Country Representative Members, Members at Large, and Associate Members. The type of organization that can apply for membership is a wide variety and includes national or international societies of individual computer scientists/ICT professionals, associations or federations of such societies, government institutions/government related organizations, national or international research institutes or consortia, universities, academies of sciences, companies, national or international associations or federations of companies.

More information about this series at http://www.springer.com/series/6102 
Daoliang Li (Ed.)

\section{Computer and \\ Computing Technologies in Agriculture $\mathrm{X}$}

10th IFIP WG 5.14 International Conference, CCTA 2016 Dongying, China, October 19-21, 2016 Proceedings 


\title{
Editor
}

\author{
Daoliang Li \\ China Agricultural University \\ Beijing, China
}

\author{
ISSN 1868-4238 ISSN 1868-422X (electronic) \\ IFIP Advances in Information and Communication Technology \\ ISBN 978-3-030-06154-8 \\ ISBN 978-3-030-06155-5 (eBook) \\ https://doi.org/10.1007/978-3-030-06155-5
}

\section{Library of Congress Control Number: 2018964697}

(C) IFIP International Federation for Information Processing 2019

This work is subject to copyright. All rights are reserved by the Publisher, whether the whole or part of the material is concerned, specifically the rights of translation, reprinting, reuse of illustrations, recitation, broadcasting, reproduction on microfilms or in any other physical way, and transmission or information storage and retrieval, electronic adaptation, computer software, or by similar or dissimilar methodology now known or hereafter developed.

The use of general descriptive names, registered names, trademarks, service marks, etc. in this publication does not imply, even in the absence of a specific statement, that such names are exempt from the relevant protective laws and regulations and therefore free for general use.

The publisher, the authors, and the editors are safe to assume that the advice and information in this book are believed to be true and accurate at the date of publication. Neither the publisher nor the authors or the editors give a warranty, express or implied, with respect to the material contained herein or for any errors or omissions that may have been made. The publisher remains neutral with regard to jurisdictional claims in published maps and institutional affiliations.

This Springer imprint is published by the registered company Springer Nature Switzerland AG The registered company address is: Gewerbestrasse 11, 6330 Cham, Switzerland 


\section{Preface}

The 10th International Conference on Computer and Computing Technologies in Agriculture (CCTA 2016) was held in Dongying, China, during October 19-21, 2016.

The conference was hosted by the China Agricultural University (CAU), Information Technology Branch of China Animal Husbandry and Veterinary Association. It was sponsored by the Chinese Society of Agricultural Engineering (CSAE), the Kenli District Government, Da Bei Nong Group, Beijing Nong Xintong Technology Co. Ltd.

In order to promote the exchange and cooperation among scientists and professionals from different fields and to strengthen international academic exchange, the Information and Modern Agriculture Joint Conference includes the IFIP International Conference on Computer and Computing Technologies in Agriculture (10th CCTA) and the Academic Symposium of Information Technology Branch of China Animal Husbandry and Veterinary Association. These events provide a platform, for experts and scholars from all over the world to exchange techniques, ideas, and views on intelligent agricultural innovation. These experts and scholars from all over the world exchange the new theories, views, technologies, and products and share practical experiences in research and applications in intelligent agriculture innovation. Nine international CCTA have been held since 2007.

The topics of CCTA 2016 covered the theory and applications of all kinds of technology in agriculture, including intelligent sensing, cloud computing, key technologies of Internet of Things, precision agriculture, etc.; animal husbandry information technology, including Internet and modern animal husbandry, livestock big data platform and cloud computing applications, intelligent breeding equipment, precision production models, etc.; water product networking and big data, including fishery IoT, aquaculture intelligent facilities, big data applications, etc.

We selected the 54 best papers among the 128 papers submitted to CCTA 2016 for these proceedings. All papers underwent two reviews by experts from the Special Interest Group on Advanced Information Processing in Agriculture (AIPA), IFIP. In these proceedings, creative thoughts and inspirations can be discovered, discussed, and disseminated. It is always exciting to have experts, professionals, and scholars with creative contributions getting together to share inspiring ideas and to accomplish great developments in the field.

I would like to express my sincere thanks to all authors who submitted research papers to the conference. Finally, I would also like to express my gratitude to all speakers, session chairs, and attendees, both national and international, for their active participation and support of this conference. 


\section{Conference Organization}

\section{Organizers}

China Agricultural University

Information Technology Branch of China Animal Husbandry and Veterinary

Association

International Federation for Information Processing (IFIP)

\section{Sponsors}

Chinese Society of Agricultural Engineering (CSAE)

Da Bei Nong Group

Ministry of Agriculture, China (MOA)

Ministry of Science and Technology, China (MOST)

Beijing Municipal Science and Technology Commission (BMSTC)

Beijing Association for Science and Technology, China (BAST)

Dabeinong Education Foundation, China

Beijing Nong Xintong Technology Co. Ltd.

\section{Organizing Committee}

Daoliang Li College of Information and Electrical Engineering, China Agricultural University

Benhai Xiong Beijing Animal Husbandry and Veterinary Research Institute, Chinese Academy of Agricultural Sciences

Nick Sigrimis Agricultural University of Athens, Greece

Liping Chen China National Engineering Research Center of Intelligent Equipment for Agriculture

Xinting Yang China National Engineering Research Center for Information Technology in Agriculture

\section{Program Committee}

Daoliang Li College of Information and Electrical Engineering, China Agricultural University

Benhai Xiong

Beijing Animal Husbandry and Veterinary Research Institute, Chinese Academy of Agricultural Sciences

Zhenbo Li

College of Information and Electrical Engineering, China Agricultural University

Yingyi Chen

College of Information and Electrical Engineering, China Agricultural University 
Yaoguang Wei College of Information and Electrical Engineering, China Agricultural University

Qingling Duan College of Information and Electrical Engineering, China Agricultural University

Longqing Sun

College of Information and Electrical Engineering, China Agricultural University

Ming Sun

College of Information and Electrical Engineering, China Agricultural University

Xiaoshuan Zhang College of Information and Electrical Engineering, China Agricultural University

Chunhong Liu

College of Information and Electrical Engineering, China Agricultural University

Weizhong Yang

College of Information and Electrical Engineering, China Agricultural University

\section{Chairmen}

Daoliang Li and Benhai Xiong

\section{Conference Secretariat}

Xia Li 


\section{Contents}

Study on the Theory and Practice of Data Visualization. . . . . . . . . . . 1 Quan Wu, Xiaochen Li, Danqiong Wang, Weijie Jiao, and Xue Han

Assessing the Ability of Image Processing Methods of Droplets Sprayed on Water Sensitive Papers for Aerial Application . . . . . . . . . . . . .

Gang Xu, Ruirui Zhang, Liping Chen, Qing Tang, Min Xu, and Wanmin Zhang

Application of "GaoFen-1" Satellite Data and "Micro-UAV" Data in Remote Sensing Monitoring in Winter Wheat-Illustrated

by a Case of Jizhou in Hebei Province . . . . . . . . . . . . . . . . .

Yuechen Liu, Weijie Jiao, Haijun Wang, and Xue Han

Research on Reflectance Spectra Measurement of Chlorophyll-Containing Water in Laboratory . . . . . . . . . . . . . . . . . . . . . . . . . .

Yinchi Ma, Yetao Li, Yonghua Qu, and Wen Ding

Study on Simulation of Rice Yield with WOFOST

in Heilongjiang Province . . . . . . . . . . . . . . . .

Shangjie Ma, Zhiyuan Pei, and Yajuan He

Application of the Data from Landsat8 OLI - The New Generation of Landsat Series in the Cultivated Land Information Extraction . . . . . . . . .

Luyan Niu, Taichang Cui, Jiabo Sun, and Xiaoyan Zhang

Research on High Precision pH Sensing Device Based on Cloud Platform Service . . . . . . . . . . . . . . . . . . . . . . . . . . . . . . . .

Zhiyue Shang, Xin Zhang, Cheng Zeng, Yuanfang Yao, Yunlong Bu, and $\mathrm{Yu} \mathrm{Cai}$

Effects of Waterlogging and Shading at Jointing Stage on Dry Matter

Distribution and Yield of Winter Wheat. ..................

Yang Liu, Xiaoyu Liu, Jing Cao, Chunlin Shi, and Shouli Xuan

Identification of Eggplant Young Seedlings Infected by Root Knot

Nematodes Using Near Infrared Spectroscopy. . . . . . . . . . . . . . . . . . . . .

Wei Ma, Xiu Wang, Lijun Qi, and Dongyan Zhang

Applicability of Model Updating Method to Different Detection Indexes of Cold Fresh Pork . . . . . . . . . . . . . . . . . . . . . . . . .

Shanmei Liu, Hui Peng, Ruifang Zhai, and Jun Luo 
Detection of Defects in Malus asiatica Nakai Using

Hyperspectral Imaging. . . . . . . . . . . . . . . . . . . . . . .

Jianglong Liu, Shujuan Zhang, Haixia Sun, and Zhiming Wu

Study and Development of the Precision Management System

for Livestock . . . . . . . . . . . . . . . . . . . . . . . . . . . . .

Fengyun Wang, Wenjie Feng, Jiye Zheng, and Huaijun Ruan

Kinematic Simulation of Vibrating Disc No-Till Seeder

Based on Creo Software . . . . . . . . . . . . . . . . . . . . . .

Caiyun Lu, Zhijun Meng, Xiu Wang, Guangwei Wu, Liwei Li,

Weiqiang $F u$, and Jiayang $Y u$

Calculation of Effective Rainfall in the Spring Maize Growing Period . . . . . .

Nana Han, Gangyan Lou, Yangren Wang, Qingyun Zhou, Jianhua Jin, Songmin Li, and Lantao Ye

Simulation of Evaporation and Transpiration of Eggplant Under Mulch

Drip Irrigation in Greenhouse . . . . . . . . . . . . . . . . . . .

Zhiwei Zheng, Liuyan Yu, and Xiushui Liu

Design and Development of Greenhouse Energy Management Platform

Based on STM32 .........................

Junlin Sun, Xin Zhang, Cheng Zeng, Wengang Zheng, Lipeng Guo, and Yali Du

Study on the Dynamic Low Limit of Irrigation for Winter Wheat . . . . . . . . Hongzheng Shen and Yangren Wang

Research on Plant Growth Simulation Method Based on ARToolkit . . . . . . . Peng-fei Zhao, Tian-en Chen, Wei Wang, and Fang-yi Chen

Control System Design of Soy Sauce Koji-Making Based on ARM. . . . . . . . Min Zhang, Yuhua Wu, Ting Yang, and Shijun Li

Research on the Comprehensive Evaluation of Alfalfa Management

in Zuli River Basin . . . . . . . . . . . . . . . . . . . . . . . . . . . . 204 Rui Guo, Cui Yun Wang, Xue Ying Shang, and Xuan Mi

Fruit Tree Image Registration Based on Improved FAST Algorithm . . . . . . . Juan Feng, Lihua Zeng, and Jianping Li

Development of a Recognition System for Alfalfa Leaf Diseases

Based on Image Processing Technology. . . . . . . . . . . . . . . . . . . . . . . 218 Feng Qin and Haiguang Wang 
Design Optimization and Performance Evaluation of a Tillage Depth

Precision Measurement System. . . . . . . . . . . . . . . . . .

Kang Niu, Yanwei Yuan, Junning Zhang, Fengzhu Wang, Yangchun Liu,

Xianfa Fang, and Hong Cheng

Research on Evaluation of Soil Fertility Resource Space Based

on Regional Hotspots and Clustering Method . . . . . . . . . . . . .

Guifen Chen, Jian Lu, Ying Meng, and Dongxue Wang

Research on GA-RBF Optimization Algorithm in the Prediction

of Yield Loss of Maize Diseases and Pests. . . . . . . . . . . . . . . .

Guifen Chen, Dongxue Wang, Shan Zhao, and Siwei Fu

The Association Rules Algorithm Based on Clustering in Mining

Research in Corn Yield . . . . . . . . . . . . . . . . . . . .

Bo Liu and Guifen Chen

Application of Principal Component Cluster Analysis in the Quality

of Cordyceps Sinensis . . . . . . . . . . . . . . . . . . . . .

Xin Zhao, Hongjian Yang, Yuqi Sheng, Yang Jiao, Haijiao Yu, Yao Qin,

and Guogang Zhao

Principal Component Clustering Analysis Apply to the Amino Acid

Content in Antler Based on Matlab . . . . . . . . . . . . . . . . . .

Xin Zhao, Jing Wang, Yang Jiao, Haijiao Yu, Yao Qin, Quanming Li,

and Guogang Zhao

The Principal Component Analysis and Cluster Analysis of Trace

Elements in Gentian . . . . . . . . . . . . . . . . . . . . . . .

Xin Zhao, Mingwei Xu, Guoqing Sun, Yang Jiao, Haijiao Yu,

Quanming Li, and Guogang Zhao

Research on Color and Shape Recognition of Maize Diseases

Based on HSV and OTSU Method . . . . . . . . . . . . . . . . . . .

Guifen Chen, Ying Meng, Jian Lu, and Dongxue Wang

Research on Variation Rule of Sensible Heat Flux in Field Under

Different Soil Moisture Content and Underlying Surface by Large Aperture

Scintillometer .

Xin Han, Qingyun Zhou, Baozhong Zhang, and Di Xu

Design Method for Chemical Clogging Emitters Boundary Optimization . . . .

$X u$ Li, Peiling Yang, Shumei Ren, Lili Zhangzhong, and Lihong Yang

Strategies of Agricultural Manufacturing Industrial Cluster Knowledge

Service Platform Construction and Optimization: The Case

of Shandong Province ........................

Qiong He and Minli Yang 
Application of GIS and Modified DRASTIC Model Based on Entropy

Weight and Fuzzy Theory to Ground Water Vulnerability Evaluation . . . . . .

Shaofei Li and Guanyou Li

Simulation Research on Water Quality in the Irrigation Section

of Jinsha River . . . . . . . . . . . . . . . . . . . . .

$\mathrm{Xu}$ Wang and Ping Yu

Research on Virtual Simulation of Flood Propagation in Agricultural Area

Under the Land Subsidence . . . . . . . . . . . . . . . . . . . . . . .

Ping Yu, Shaofei Li, and Xu Wang

Research on the Clustering Method of Agricultural Scientific Data Based on the Author's Scientific Research Relationship . . . . . . . . . . . . . . .

Dingfeng Wu, Liyun Wang, Jian Wang, Hua Zhao, and Guomin Zhou

Evaluating E-Service Quality of Agricultural Business Websites in China:

E-S-QUAL Model Approach . . . . . . . . . . . . . . . . . . .

Ke Sun, Yan Li, Yiliang Wang, $\mathrm{Xi} W u$, and Yiming Huang

Design of Agaricus Bisporus Automatic Grading System Based

on Machine Vision . . . . . . . . . . . . . . . . . . . .

Jiye Zheng, Wenjie Feng, Bingfu Liu, and Fengyun Wang

Study on China-Laos Forestry Cross-Border Cooperation Strategy Model. . . . $\mathrm{Yu} \mathrm{He}$

The Monitoring System for Agricultural Environment Based on Point

Surface Fusion with the Internet of Things and WebGIS . . . . . . . . . . 406 Guifen Chen and Yinglun $\mathrm{Li}$

Study on Social Stability Risk Detection of Large Hydraulic Project

Construction Based on Social Vulnerability Evaluation . . . . . . . . . . . Aihua Wu, Changzheng Zhang, and Ma Zhijie

Research on Intelligent Decision of Pulmonary Tuberculosis Disease

Based on Data Mining. . . . . . . . . . . . . . . . . . . . .

Guifen Chen, Wang Ke, and Ma Li

Removing Stray Noise Quickly from Point Cloud Data Based on Sheep Model . . . . . . . . . . . . . . . . . . . . . . . . .

Chunlan Wang, Heru Xue, Xinhua Jiang, Yanqing Zhou, and Liyan Wang

Modelling and Predicting of Soil Electrical Conductivity and PH from

Semi-arid Grassland Using VIS-NIR Spectroscopy Technology. . . . . . . . . . . ShangBin Lei, NiSha Bao, ShanJun Liu, and XiaoCui Liu 
Effect of Plants Combination in Purifying Farmland Drainage . . . . . . . . .

Songmin Li, Qingyun Zhou, Nana Han, and Shuhong Sun

Problems and Countermeasures of $3 \mathrm{~S}$ Technologies Application

in Precision Agriculture . . . . . . . . . . . . . . . . . . . . . . 464

Qiulan Wu, Zhihong Liu, Dandan Yang, and Zhenrong Han

Feature Selection for Cotton Matter Classification . . . . . . . . . . . . . . 473

Xuehua Zhao, Ying Huang, Zhao Li, Shukai Wu, Xiuhong Ma, Hua Chen, and Xu Tan

Effect of Calibration Set Selection on Quantitatively Determining Test

Weight of Maize by Near-Infrared Spectroscopy . . . . . . . . . . . . . . . .

Lianping Jia, Peng Jiao, Junning Zhang, Zhen Zeng, and Xunpeng Jiang

Research on Method of Image Extraction for Crop Monitoring with Multi Rotor UAV ........................

Wei Ma, Xiu Wang, Lijun Qi, and Cuiling Li

Prediction of Drying Indices for Paddy Rice in a Deep Fixed-Bed

Based on Neural Network . . . . . . . . . . . . . . . . . . . . .

Danyang Wang, Chenghua Li, Benhua Zhang, and Ling Tong

Definition Management Zones of Drip Irrigation Cotton Field

Based on the GIS and RS .....................

Ze Zhang, Zhouyang Li, Lulu Ma, Xin Lv, and Lifu Zhang

A Survey on Development of "Internet + Farmer Cooperative" in China . . . .

Guo-peng Zhang, Jie-ling Zou, Jing Hua, Li-ming Wang, Jing-shun Du, and Yu-bin Wang

Hyperspectral Estimation of Leaf Area Index of Winter Wheat

Based on Akaike's Information Criterion . . . . . . . . . . . . . . . . . . .

Haikuan Feng, Fuqin Yang, Guijun Yang, and Haojie Pei 